\title{
PALABRAS PRELIMINARES DEL PRESIDENTE DE LA SOCIEDAD DE FILOSOFIAA MEDIEVAL
}

\author{
Preliminary Words by the President by the Sociedad de Filosofía Medieval
}

\section{Homenaje a tres fundadores y una revista para el futuro}

Es este un número destacado en la historia de la Revista Española de Filosofía Medieval, la publicación anual de la Sociedad de Filosofía Medieval. En él se concretizan cambios significativos en su estructura editorial para prepararla de cara al futuro, al tiempo que se publican dos homenajes in memoriam: del Profesor Dr. Joaquín Lomba Fuentes (promotor, miembro fundador, primer Presidente y Presidente de Honor de la Sociedad) y del Profesor Dr. César Lorenzo Raña Dafonte (también uno de los fundadores de la Sociedad, además de presencia habitual en sus actividades). A modo de homenaje por toda sua labor, dedicamos el dossier principal al Profesor Dr. Jorge Ayala Martínez, director de la Revista desde su fundación.

El volumen inaugural de la Revista Española de Filosofía Medieval (REFIME), publicado en 1993, tiene el número 0 , lo que es habitual en la prensa diaria pero excepcional en revistas científicas. Ese número 0 fue «un ensayo y un sondeo», como se decía en la presentación del volumen 1 publicado al año siguiente. Un ensayo, debe decirse, plenamente logrado, dados sus 29 artículos, autores de múltiples y diferentes instituciones, así como la diversidad de temas y de orientaciones metodológicas — características que marcarán todos los volúmenes posteriores. La decisión de fundar la Revista ocurrió simultáneamente con la decisión de fundar la Sociedad de Filosofía Medieval (SOFIME), adoptada en el I Congreso de Filosofía Medieval, celebrado en la Universidad de Zaragoza entre el 12 y el 14 de diciembre de 1990 a iniciativa de Joaquín Lomba Fuentes, que firma la presentación de las respectivas Actas publicadas en Zaragoza en 1992, un año antes del número 0 de la Revista. Aquellos años de 1990 a 1993, con el nacimiento de estos trillizos que continúan en crecimiento (la Sociedad, la Revista, el Congreso cuatrienal), marcan de forma decisiva una ampliación en el reconocimiento público de los estudios sobre Filosofía Medieval no sólo en España, sino en toda Iberoamérica, haciendo más conocido el intenso trabajo que se venía realizando. Un gran número de profesores e investigadores pasan a congregarse en torno a SOFIME y su Revista, ambas con sede en la Universidad de Zaragoza y el apoyo de su Departamento de Filosofía.

Como podemos leer en el sentido y documentado perfil que el Profesor Dr. Rafael Ramón Guerrero le dedica al inicio de este volumen, Joaquín Lomba Fuentes, además de su primer impulsor, fue un perseverante y dinámico presidente de la Sociedad hasta 2004, año en que fue proclamado Presidente de Honor en la Asamblea que ese año tuvo lugar en Córdoba. Su actividad, y la de los miembros de la Junta que con él colaboraron, permitió consolidar la Sociedad, asegurando la realización y publicación de las Actas de los tres primeros Congresos - de las cuales escribió los prefacios. A lo largo de los años, cuando no podía estar presente en las asambleas anuales de la Sociedad, siempre enviaba, a través de Rafael Ramón, su saludo y palabras de estímulo a todos los miembros, algo que no ocurrió en la Asamblea reunida el 6 de marzo de 2018, lo que dejaba entrever ya la debilidad de su estado de salud, conociendo posteriormente, y para gran consternación de todos, que había fallecido el día anterior. Por todo ello es de entera justicia que la Sociedad y la Revista presten ahora un sentido homenaje in memoriam a Joaquín Lomba Fuentes, del cual se ha encargado el Profesor Rafael Ramón Guerrero que, además de la larga y mutua amistad, compartía con él la pasión por el pensamiento árabe medieval, siendo también compañero suyo en la fundación, dinamización e internacionalización de la Sociedad.

El Profesor Dr. César Lorenzo Raña Dafonte, catedrático de Filosofía Medieval en la Universidad de Santiago de Compostela, que también participó en la fundación de SOFIME en aquel Congreso de 
1990 en Zaragoza, fue a lo largo del tiempo una continua presencia en las páginas de la Revista, donde publicó numerosos artículos y traducciones, casi siempre dedicadas a temas y autores del siglo XII, temas en los que ha sido un reconocido especialista. Falleció en noviembre de 2018, poco después de que la Sociedad y la Universidad de Santiago de Compostela hubieran anunciado la realización en dicha sede de un coloquio bajo el título «De amicitia. La amistad en la filosofía medieval e inicios de la modernidad. Homenaje al Prof. César Raña Dafonte» (21 al 22 de abril de 2019). Anticipándonos a ese homenaje desde estas páginas: su discípulo el Profesor Dr. Martín González Fernández publica una laudatio in memoriam, el Profesor Dr. José Luis Fuertes Herreros le dedica un estudio donde celebra sus intereses por la Filosofía Medieval y todo lo publicado en la Revista Española de Filosofía Medieval.

El Profesor Dr. Jorge Ayala Martínez, también docente de Filosofía Medieval en la Universidad de Zaragoza, fue sin duda el más cercano colaborador de Joaquín Lomba. Desde un primer momento acompañó todas las iniciativas de la fundación de SOFIME, de la publicación de la Revista y de la organización y publicación de las Actas de los primeros congresos. Elegido primer secretario de SOFIME desde la fundación en 1990, se le atribuyó la responsabilidad de la dirección de la Revista que, después de ese «ensayo» con el número 0, ya asumió desde el número 1. Hasta el volumen 24 de 2014 fue director de esta revista, ocupándose no sólo de las tareas editoriales sino también de todas las etapas de producción, desde el contacto con autores, hasta la impresión y distribución, dirección que además compartió con los nuevos editores hasta 2017. Un trabajo impresionante, hecho con brío, dedicación y puntualidad. $\mathrm{Si}$ alineamos todos los volúmenes y tenemos en cuenta las densas páginas de texto, comprenderemos mejor el inmenso trabajo consistente en editar veinticuatro volúmenes, con centenares de artículos y recensiones, redactando incluso las noticias relativas a la Sociedad. La Junta de SOFIME y los nuevos editores de la Revista no podían dejar de publicar un homenaje a su primer director, lo que ahora realizamos a través de un testimonio de reconocimiento a varias voces, en el que participan los Profesores José María Andreu Celma, Rafael Ramón Guerrero, María Jesús Soto Bruna y Celina Lértora de Mendoza.

Al acercarse a su jubilación, el Prof. Jorge Ayala fue preparando su sustitución en las diversas funciones que asumió. En 2008, en el Congreso de Alcalá de Henares el Dr. Pedro Mantas España de la Universidad de Córdoba asumió la función de secretario de SOFIME, manteniéndose la sede en Zaragoza. La Sociedad necesitó algún tiempo para realizar un cambio de sede, lo que obligó a complicadas y dilatadas gestiones burocráticas concluidas con la actual secretaria, la Dra. María Martín Gómez y con el traslado de SOFIME en 2018 a la Universidad de Salamanca.

También resultaba necesario encontrar un equipo con el que distribuir las numerosas tareas editoriales que Jorge Ayala había realizado a solas durante mucho tiempo. En primer lugar se aseguró la continuidad de la Revista con la codirección (en 2016 y 2017) de Rafael Ramón Guerrero, que aportó a la Revista toda su experiencia como director de los Anales del Seminario de Historia de la Filosofía (de la Universidad Complutense de Madrid), revista que dirigió durante varios años. Su trabajo permitió iniciar una consolidación de procedimientos para adoptar las actuales exigencias de revisión por pares y clasificación de las revistas, que hoy resultan fundamentales para su reconocimiento por parte de las agencias de evaluación académica y de acreditación. Al mismo tiempo, SOFIME, impulsada por Pedro Mantas España, entonces secretario de la Sociedad había decidido publicar la Revista en acceso abierto a través de la plataforma Open Journal System — manteniendo la edición impresa bajo la responsabilidad de las Prensas Universitarias de Zaragoza. Después del acuerdo con Zaragoza para la cesión del registro, fue posible integrar las dos ediciones, impresa y en OJS, en UCOPress (editorial de la Universidad de Córdoba). A ambas editoriales agradecemos todo el anterior y actual apoyo que nos brindan.

Todas estas modificaciones se prepararon simultáneamente con la reestructuración editorial de la Revista, decidida por la Asamblea anual de SOFIME. A propuesta de la Junta Directiva, en 2017 fue nombrado un nuevo equipo editorial constituido por Alexander Fidora (anterior Presidente) y Pedro Mantas España (anterior Secretario) para asumir la dirección de la Revista y asegurar la continuidad de la publicación, preparando también una propuesta de renovación de los Consejos Editorial y Científico para seguir cumpliendo con las exigencias de rigor que caracterizan a la Revista, consolidando además su patrón de calidad internacional. El equipo editorial se completó en la Asamblea de 2018, pasando a integrar también a los asociados Nicola Polloni (ya responsable de plataformas y difusión electrónica) y 
Celia López Alcalde. Así, el equipo editorial queda constituido desde el volumen presente por tres editores (Alexander Fidora, Pedro Mantas España, Nicola Polloni) y una editora ejecutiva (Celia López Alcalde).

Una de las primeras tareas del nuevo equipo de editores ha consistido en proponer una nueva composición de la Comisión Editorial / Editorial Board y de la Comisión Científica / Advisory Board, que la Junta Directiva aprobó y está en activo desde el presente volumen: su composición se encuentra en la ficha técnica y al final de la Introducción. SOFIME agradece al equipo de editores todos los esfuerzos que está realizando para asegurar la continuidad de la Revista y agradece a todos los miembros de estas comisiones la preciosa colaboración que aceptaron darnos.

Garantizada la continuidad de esta doble aventura, SOFIME y REFIME, involucrando a profesores e investigadores de tantos centros académicos y países, se mantiene vivo el entusiasmo manifestado por Joaquín Lomba Fuentes en las Actas de los tres primeros Congresos SOFIME, y por Jorge Ayala en la presentación de cada volumen de la Revista. Siempre han celebrado la vitalidad de los estudios de Filosofía Medieval que aquí encontraban espacio privilegiado para su difusión. Es ese mismo espíritu de los fundadores que queremos seguir cultivando en el futuro, y para ello se diseñó la Revista usando las herramientas que están a nuestro alcance. A la difusión abierta se suma un número creciente de colaboradores de distintas generaciones, contribuyendo a consolidar el perfil dinámico y innovador de nuestra área de estudio. Aquí tiene su espacio el pensamiento de la Edad Media en todas las culturas y lenguas donde floreció, estudiándose los más distintos aspectos del amplio diálogo plural y contextual que la filosofía entreteje con la teología, las ciencias, la política, la sociedad y las instituciones.

SOFIME apoya sin vacilaciones todas las iniciativas para continuar esta historia de crecimiento y consistencia científica con que la Revista está comprometida desde su fundación. La puntualidad y la calidad de cada volumen dependen principalmente de los autores, a quienes debemos un agradecimiento especial por querer publicar sus investigaciones en estas páginas, y así aportar una colaboración imprescindible para el éxito y la consolidación académica de la Revista, que ya posee un lugar destacado en el panorama internacional entre las publicaciones especializadas en Filosofía Medieval.

De este modo, continuando y renovando nuestro compromiso con los Autores y Lectores, SOFIME desea proseguir el programa trazado por los fundadores: constituirse como un forum de debate y de intercambio, involucrando a instituciones y a todos los interesados en profundizar en el estudio de la Filosofía Medieval, no sólo como época de la Historia de la Filosofía — por sí misma en fase de descubrimiento y ampliación permanentes-, sino también dentro del marco del debate filosófico actual.

JOSÉ PRETO MEIRINHOS

Universidade do Porto 